\title{
DIGITALISASI POLA PAKAIAN MELALUI CLO3D (KOKREASI BERSAMA LPK NADYA JAYA \& BRAND PAKAIAN LOVADOVA)
}

\author{
Susi Hartanto ${ }^{1}$, Injo Erlyn Yulita Wiryanto
}

Program Studi Desain Produk, Fakultas Desain, Universitas Pelita Harapan

\begin{abstract}
Abstrak
Salah satu industri kreatif Indonesia yang bergerak ke arah industri 4.0 adalah fesyen. Dengan situasi pandemi dan keharusan menjaga jarak, metode digital semakin banyak dipergunakan agar proses bisnis fesyen bisa tetap berjalan, termasuk salah satunya dengan desain busana 3D. PkM ini adalah kokreasi antara Desain Produk UPH, mitra PkM (lembaga kursus LPK Nadya Jaya) dan mitra brand pakaian Lovadova; mengusung Clo3D sebagai alat bantu menghasilkan pola 3D pakaian sehingga mengurangi kesalahan, menghemat waktu, biaya, dan bisa dilakukan tanpa model tubuh asli. Ada 16 pola yang dihasilkan, 7 diantaranya diproduksi dalam bentuk pakaian jadi. Hasilnya, Clo3D memudahkan semua pihak dalam merancang, merevisi, melihat simulasi pakaian secara 3D; membuat siklus bisnis pakaian dari merancang hingga menjual jauh lebih cepat dibandingkan proses tradisional.
\end{abstract}

Keywords: Clo3D, fesyen, pola, digital, pandemi

\begin{abstract}
One of Indonesian creative industry with accelerated move to industry 4.0 is fashion. With global pandemic situation, and the need for social distancing, digital methods are widely used more than ever to keep fashion business process going continuously, one of them is $3 D$ garment design. This community service is a co-creation of UPH Product Design, community service partner (LPK Nadya Jaya) and brand partner (Lovadova); taking Clo3D as a tool to produce $3 D$ patterns, reducing human error, saving time \& costs, designing without fitting to actual human body. There are 16 patterns produced, 7 among them are mass-produced. As the result, Clo3D helps in terms of design, revise, simulate clothes in $3 D$; allowing the clothing business cycle from design to selling a lot faster than traditional process.
\end{abstract}

Keywords: Clo3D, fashion, pattern, digital, pandemic

Correspondence author: Susi Hartanto, susi.fdtp@uph.edu, Tangerang, Indonesia

This work is licensed under a $C C-B Y-N C$

\section{PENDAHULUAN}

Selain industri manufaktur dan industri jasa, industri kreatif adalah salah satu bidang industri yang memiliki peluang besar untuk berkembang pesat dalam era industri 4.0. Kementerian Perdagangan Republik Indonesia mendefinisikan industri kreatif sebagai bentuk industri yang berasal dari pemanfaatan kreatifitas, keterampilan serta bakat individu untuk menciptakan kesejahteraan serta lapangan pekerjaan dengan menghasilkan dan mengeksploitasi daya kreasi dan daya cipta individu tersebut. Secara 
umum industri kreatif di Indonesia terbagi menjadi 16 sub sektor, termasuk salah satu di dalamnya adalah fesyen (Kementerian Pariwisata dan Eknonomi Kreatif RI, 2014). Industri busana dan tekstil (fesyen) turut andil menyumbangkan 18 persen pendapatan negara. Maka dari itu, diperlukan dorongan yang kuat bagi pelaku di dunia fashion, agar pertumbuhan ini terus ada dan kian membaik ke depannya (Bekraf, 2019). Kesiapan pelaku industri kreatif menjadi faktor kunci dalam menghadapi persaingan dengan industri lain. Namun demikian, teknologi yang menyertai era industri 4.0 juga memberikan banyak peluang yang bisa dimanfaatkan dalam pengembangan industri kreatif. Tantangan yang dihadapi salah satunya adalah kemampuan sumber daya manusia yang terbatas (Nugroho, M.T., 2019).

Industri fesyen, sama seperti industri lainnya, telah lama terdampak dengan perkembangan sistem informasi dan teknologi (Sousa, et al., 2019) dan terus beradaptasi dengan dunia digital melalui perubahan proses bisnis. Perkembangan teknologi mempengaruhi proses bisnis dalam berbagai level: produksi, pemasaran, distribusi, penjualan, komunikasi (Kalbaska \& Cantoni, 2019). Di tengah pandemi pun, lowongan pekerjaan fesyen digital tetap tinggi (Ronchetti, et al., 2020). Indikasi ini memberikan tanda bahwa kedepannya, kemampuan digital akan semakin bermanfaat dalam mendukung bisnis fesyen. Dengan tantangan jaga jarak sosial, perusahaan dituntut berkembang lebih cepat ke arah digital dengan banyaknya pameran busana virtual, showroom digital, livestream commerce, dan desain busana 3D. Fokus artikel disini adalah pada desain busana 3D.

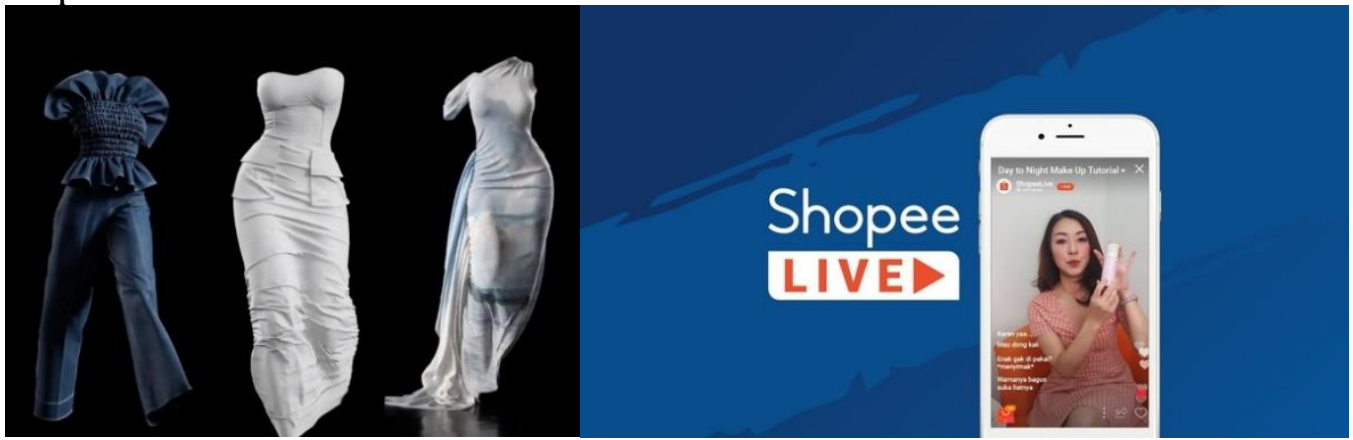

Gambar 1 Pameran Busana Virtual \& Livestream Commerce Sumber: Google, 2020

Aplikasi teknologi 3D dalam desain pola garmen adalah salah satu cara paling efisien untuk mempercepat proses desain. Untuk menyederhanakan prosedur desain dengan hasil cepat, tubuh manusia juga bisa dikreasikan dengan teknologi Clo3D, termasuk di dalamnya bentuk tubuh, bentuk kerah, bentuk lengan, aneka lipatan, sehingga menghasilkan pemodelan 3D virtual yang bisa dilihat secara instan (Li-qiang, D. O. N. G., 2014).

Metode digital tidak akan sulit diadaptasi bagi pelaku industri muda yang melek teknologi, karena pembelajaran perangkat lunak cenderung cepat apabila sudah menguasai pengetahuan manual. Namun bagi ibu-ibu PkM yang awam komputer, metode digital seperti ini dirasa asing. Namun, tanpa pembekalan konten industri 4.0, bisnis kecil menengah yang manual akan mudah tergeser seiring semakin kompetitifnya bisnis ini. Untuk itu, PkM ini mengusung isu ini, agar ketrampilan tangan ibu-ibu yang handal bisa dilengkapi pengetahuan teknologi, karena pada dasarnya setiap desain produk yang sukses membutuhkan dua kombinasi aspek ini: ketrampilan manual dan ketrampilan digital. Tujuannya bukan agar ibu-ibu PkM menjadi mahir menggunakan perangkat lunak dan komputer, tetapi agar melihat perbandingan dan manfaatnya, sehingga kedepannya 
bisa melihat metode digital sebagai opsi untuk meningkatkan daya saing. Apalagi dengan situasi pandemi covid-19, metode digital semakin banyak dipergunakan.

\section{METODE PELAKSANAAN}

PkM ini bekerja sama dengan LPK Nadya Jaya Duri Kosambi Jakarta Barat, terutama dengan Ibu Sri Wisunarsih sebagai pengajar utama. PkM ini dilaksanakan setiap minggu sejak Juni 2019 dan selesai pada Maret 2020. LPK Nadya Jaya adalah lembaga kursus yang memberikan pelatihan membuat pola dan menjahit baju bagi para siswa. Nadya Jaya juga menerima pesanan dari pelanggan untuk membuat pola atau menjahit untuk aneka jenis baju, namun umumnya adalah pakaian wanita atau baju pesta untuk kebutuhan individu. Metode yang selama ini diterapkan untuk mengajar dan mengerjakan pesanan bisnis adalah dengan cara manual. Cara manual artinya membuat pola menggunakan pensil dan kertas roti atau koran; membuat sample hasil guntingan pola kertas; dan apabila ada salah atau revisi maka harus merevisi pola kertasnya (mengulang dari awal). Cara seperti ini memang umum dipakai namun rentan revisi apabila kemampuan tukang pola kurang baik, dan akibatnya membuang waktu dan biaya untuk merevisi pakaian yang salah. Harga pola yang dipatok juga cukup mahal, sekitar Rp200.000 - 300.000 per pola, dengan tingkat akurasi pola sedang (pola bisa saja tidak sesuai). Sedangkan harga pola yang tersedia versi online dimulai dari USD2.00 dengan tingkat akurasi pola tinggi. Di era digital saat ini, ada banyak tools yang bisa dipakai untuk meminimalisasi kesalahan pembuatan pola. Di PkM ini, digunakan kombinasi Rhinoceros dan Clo3D sebagai media untuk mewujudkan pola 2D dan 3D versi komputer, sehingga adanya ketidakcocokan ataupun revisi bisa dilakukan via komputer.

Dalam periode 2 bulan, dicari 16 referensi gambar (8 pola perbulan) untuk dibuatkan pola digital 2D dan 3D. Dari 16 hasil pola yang dibuat, akan dipilihkan beberapa pola oleh mitra brand untuk dijahitkan sample, diproduksi dalam jumlah 2030pcs/sku, didokumentasikan dalam foto katalog, dan dijual untuk melihat input pasar. Selain bekerja sama dengan LPK Nadya Jaya, PkM ini bekerja sama dengan mitra brand Lovadova, sebuah brand pakaian kasual yang mengusung konsep pemakaian kain sisa hasil industri fast fashion (remnant fabrics). Brand menjual pakaian wanita dengan rentang usia 20-35 tahun dengan dress sebagai varian utama produk yang dijual. Sehingga gambar referensi yang dicari adalah perkiraan model pakaian yang bisa dijual oleh Lovadova. Kerjasama dengan 2 mitra dimaksudkan agar PkM bisa menjadi siklus penuh: merancang, memproduksi, menjual, mendapat input, dan berulang seterusnya.

\section{HASIL DAN PEMBAHASAN}

Ada 16 pola yang dihasilkan bersama mitra PkM selama bulan SeptemberOktober 2019, dan 7 diantaranya dipilih mitra brand, dijahitkan sebagai sample, diproduksi dan didokumentasikan dalam foto katalog. 


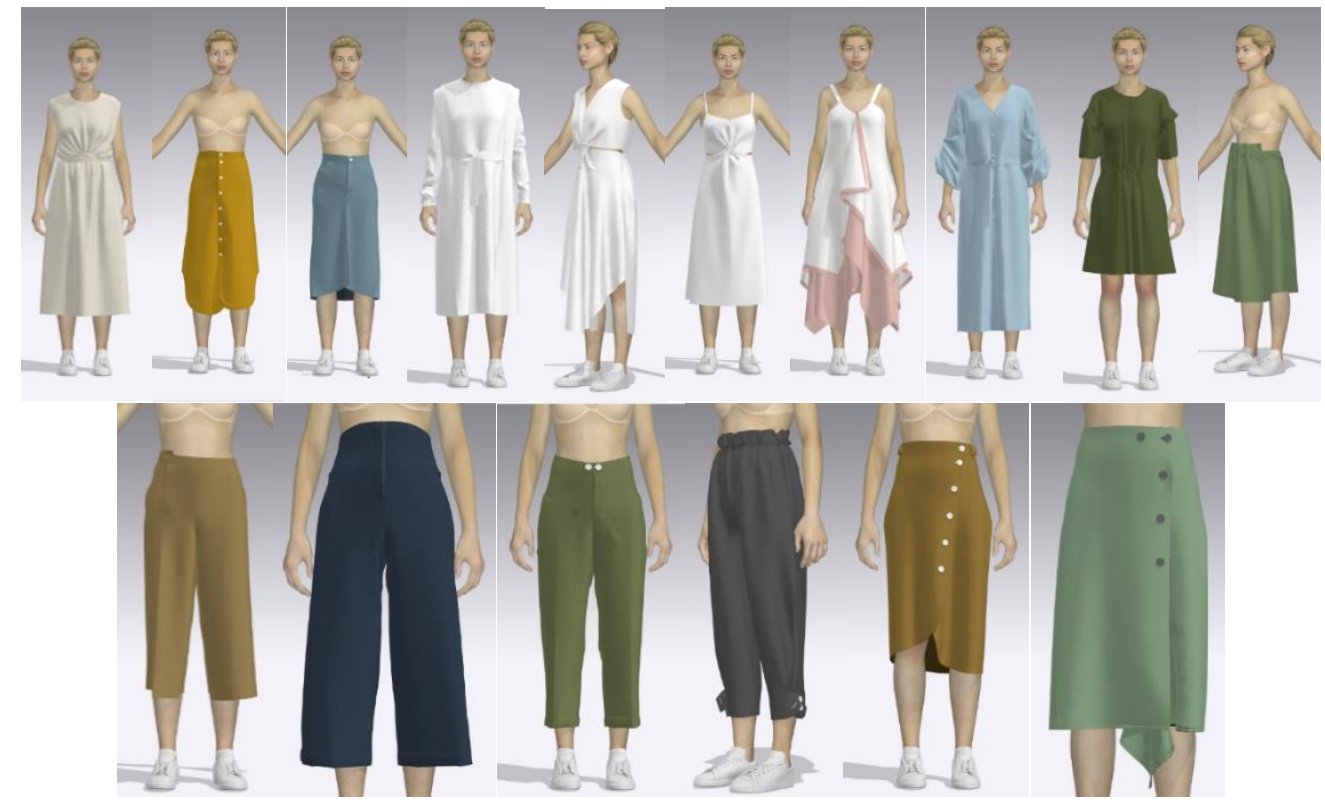

Gambar 116 Pola 3D Hasil PkM

Sumber: Hartanto \& Wiryanto, 2019

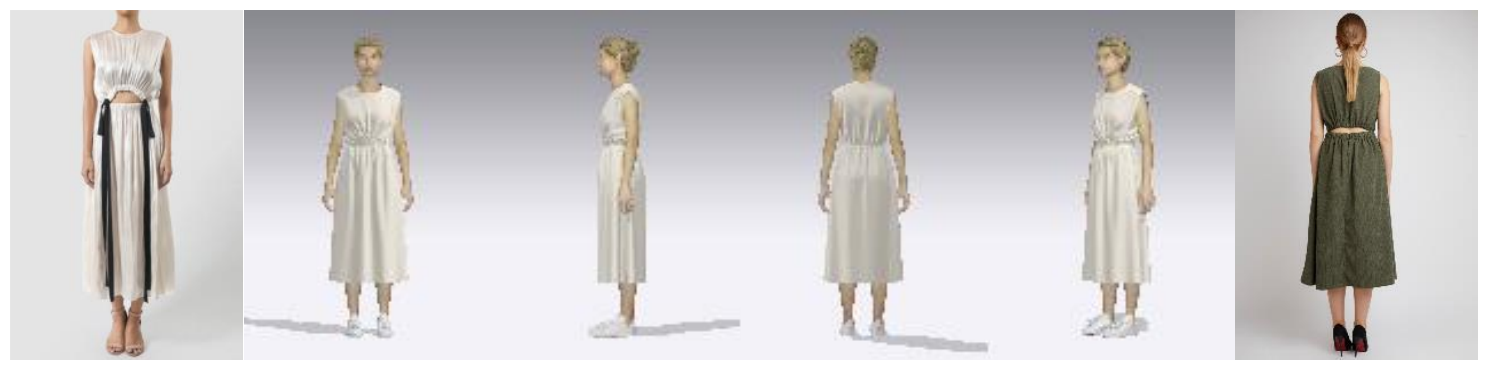

Gambar 2 Gambar Referensi - Pola 3D - Sample 20190901

Sumber: Hartanto \& Wiryanto, 2019

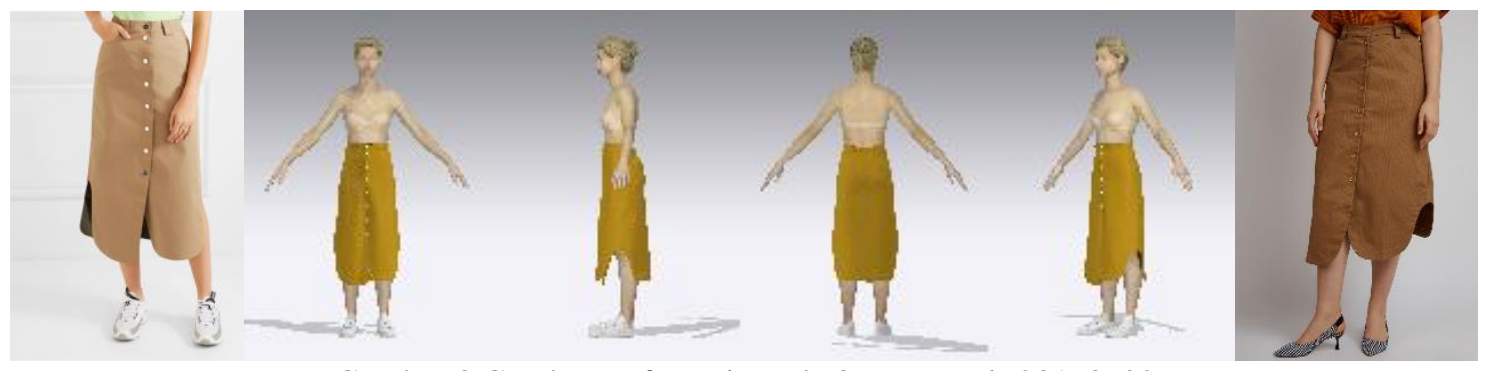

Gambar 3 Gambar Referensi - Pola 3D - Sample 20190902

Sumber: Hartanto \& Wiryanto, 2019

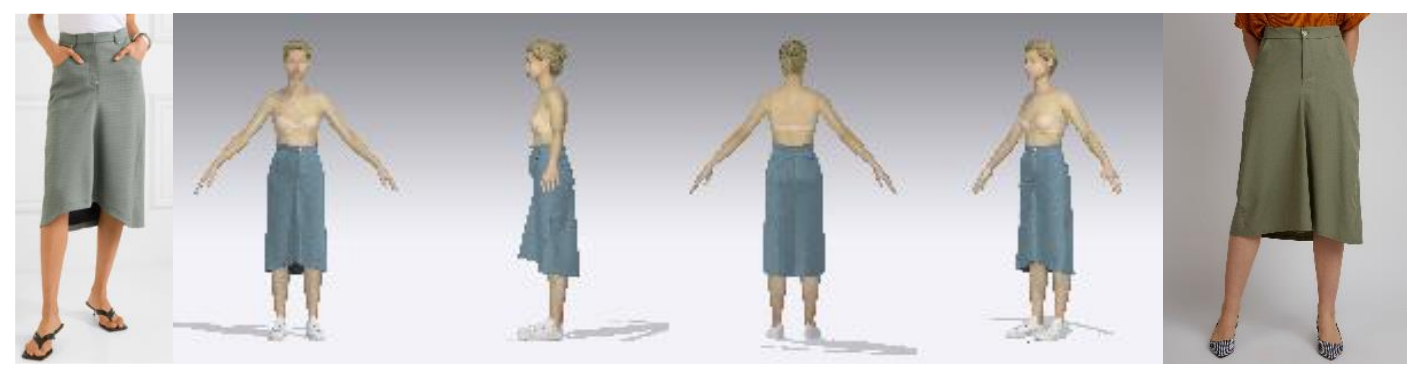

Gambar 4 Gambar Referensi - Pola 3D - Sample 20190904

Sumber: Hartanto \& Wiryanto, 2019 


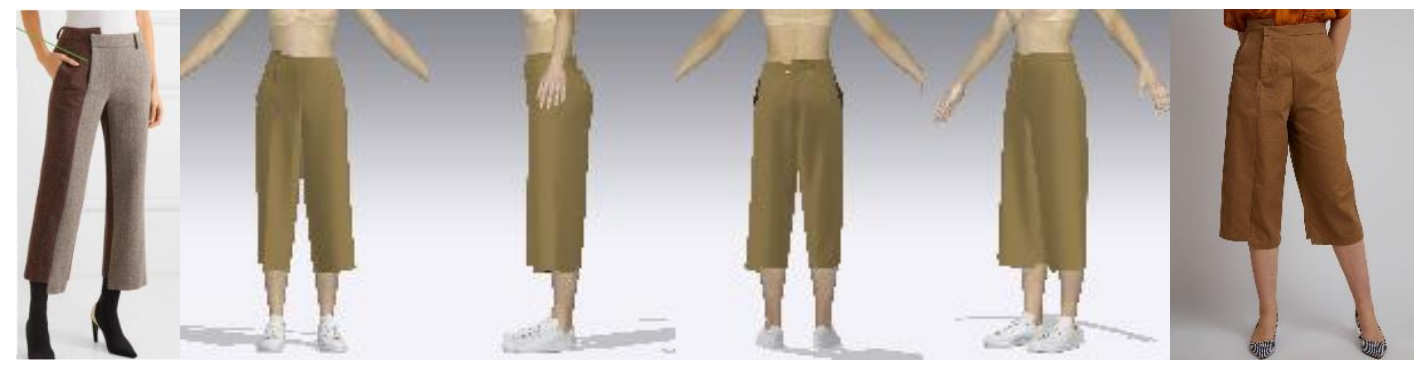

Gambar 5 Gambar Referensi - Pola 3D - Sample 20191007

Sumber: Hartanto \& Wiryanto, 2019

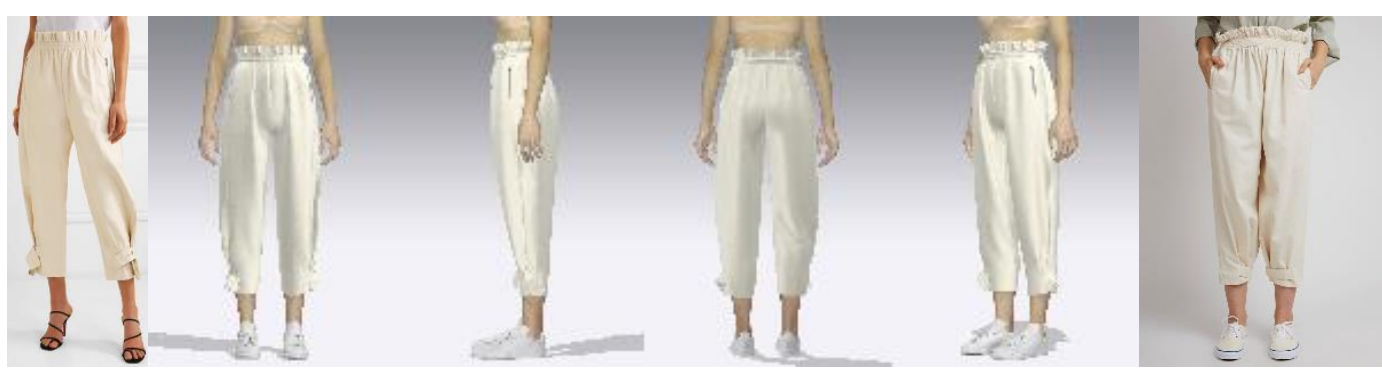

Gambar 6 Gambar Referensi - Pola 3D - Sample 20191010

Sumber: Hartanto \& Wiryanto, 2019

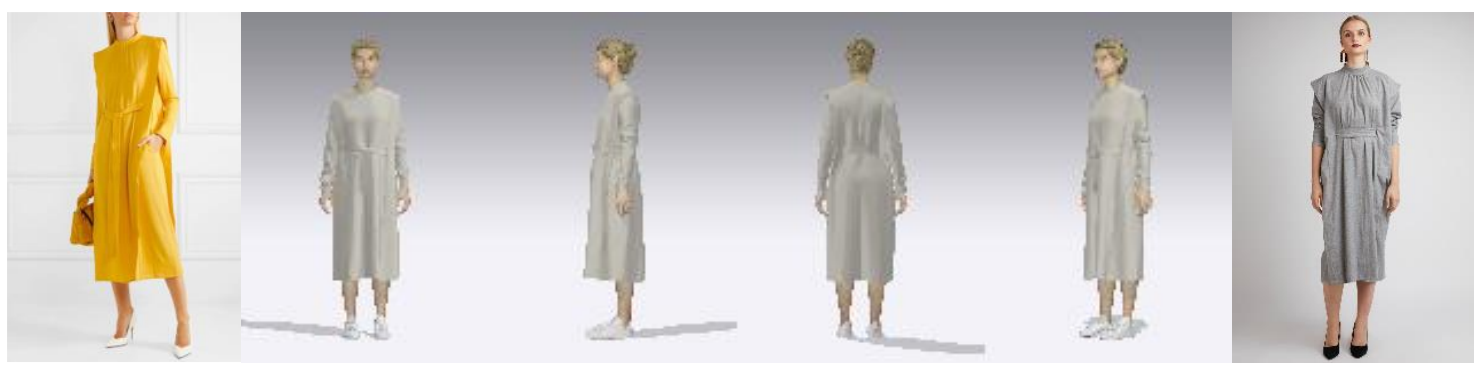

Gambar 7 Gambar Referensi - Pola 3D - Sample 20191011

Sumber: Hartanto \& Wiryanto, 2019

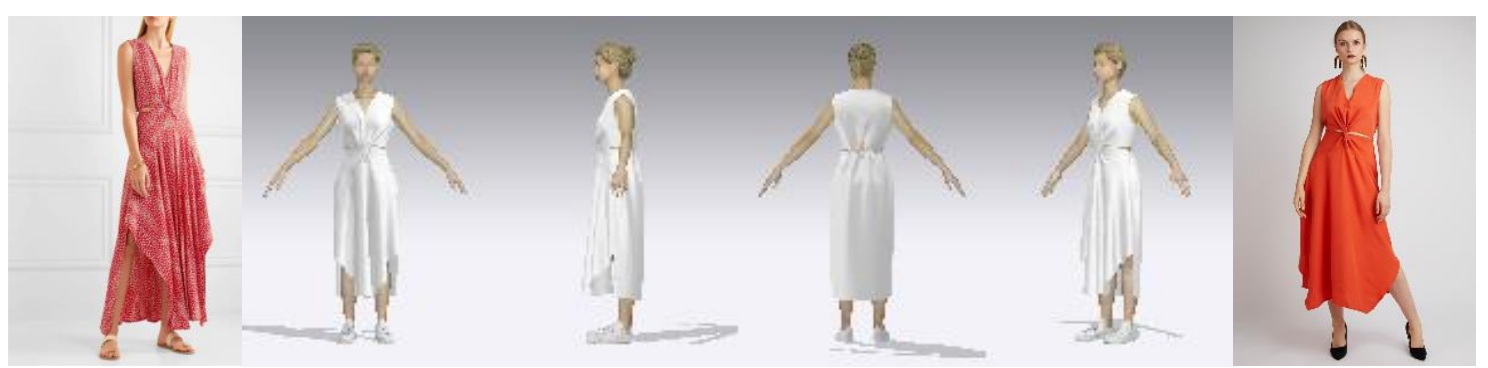

Gambar 8 Gambar Referensi - Pola 3D - Sample 20191012

Sumber: Hartanto \& Wiryanto, 2019

\section{SIMPULAN}

Selama proses pembuatan 16 pola digital, berikut manfaat yang dirasakan mitra PkM dan mitra brand menggunakan tools Rhinoceros \& Clo3D:

1. Hasil pakaian jadi dan tampak pakaian bisa terlihat jelas menggunakan avatar, sehingga ketidakcocokan detail (ukuran, panjang, lipatan, belahan, warna kain, kancing, dan sebagainya) bisa direvisi seketika menggunakan komputer. 
2. Ukuran badan avatar bisa disesuaikan sehingga sangat bermanfaat terutama bagi klien butik atau custom (baju nikah, kebaya, dan sebagainya) yang memang sering dikerjakan mitra PkM. Untuk hasil PkM ini, avatar menggunakan ukuran model standar yang sering digunakan untuk model katalog.

3. Hanya dibutuhkan waktu 1-2 jam untuk menghasilkan 1 pola, dibandingkan cara manual yang jauh lebih lama dan tidak terbayang hasilnya seperti apa.

4. Hasil render Clo3D memudahkan staff pola mitra brand untuk mengerti pola 2D yang diterima.

5. Ada banyak alternatif detail yang bisa dihasilkan dari 1 pola, memberikan keleluasaan untuk memilih hasil yang terbaik.

Unit bisnis apapun, baik itu lembaga kursus, UMKM, produsen pakaian, brand pakaian, dan lainnya wajib berinovasi untuk tetap memiliki daya saing. Paparan ini bukan dimaksudkan agar mitra PkM menjadi ahli menggunakan komputer, melainkan agar mitra PkM bisa melihat manfaat tools digital untuk melengkapi ketrampilan manual dan tidak resisten menerima metode baru yang bisa berpotensial bermanfaat apabila distrategikan dengan baik dalam rangka menyambut industri 4.0 yang sudah di depan mata.

\section{UCAPAN TERIMA KASIH}

Terima kasih kepada LPPM UPH yang telah membantu mendanai PkM ini dengan No PM-051-SoD/V/2019.

\section{DAFTAR PUSTAKA}

Kalbaska, N., \& Cantoni, L. (2019). Digital Fashion Competences: market practices and needs. In R. Rinaldi \& R. Bandinelli (Eds). Business Models and ICT Technologies for the Fashion Supply Chain, 125-135. Springer, Cham

Li-qiang, D. O. N. G. (2014). On the Application of CLO3D in Fast Garment Pattern Design. Journal of Zhejiang Textile \& Fashion Vocational College, (2), 10.

Nugroho, M. T. (2019). Industri Kreatif berbasis Budaya Peluang dan Tantangan di Era Industry 4.0. IENACO (Industrial Engineering National Conference) 72019.

Ronchetti, M., Nobile, T. H., Oliveira, N. K., \& Cantoni, L. (2020). Digital Fashion Competences: Market Practices and Needs during Covid19.

Sousa, M. J., \& Rocha, Á. (2019). Skills for disruptive digital business. Journal of Business Research, 94, 257-263

https://nadyajaya.com/, diakses pada Desember 2019

https://www.lovadova.id, diakses pada Agustus 2020

https://www.zalora.co.id/lovadova-indonesia/, diakses pada Agustus 2020 